\title{
Structural basis of chaperone-subunit complex recognition by the type 1 pilus assembly platform FimD
}

\author{
Mireille Nishiyama ${ }^{1}$, Reto Horst ${ }^{1,3}$, \\ Oliv Eidam², Torsten Herrmann", \\ Oleksandr Ignatov ${ }^{1}$, Michael Vetsch ${ }^{1}$ \\ Pascal Bettendorff', Ilian Jelesarov², \\ Markus G Grütter ${ }^{2}$, Kurt Wüthrich', \\ Rudi Glockshuber ${ }^{1, *}$ and Guido Capitani ${ }^{2, *}$
}

${ }^{1}$ Institut für Molekularbiologie und Biophysik, Eidgenössische Technische Hochschule Hönggerberg, Zürich, Switzerland and ${ }^{2}$ Biochemisches Institut, Universität Zürich, Zürich, Switzerland

Adhesive type 1 pili from uropathogenic Escherichia coli are filamentous protein complexes that are attached to the assembly platform FimD in the outer membrane. During pilus assembly, FimD binds complexes between the chaperone Fimc and type 1 pilus subunits in the periplasm and mediates subunit translocation to the cell surface. Here we report nuclear magnetic resonance and X-ray protein structures of the $\mathrm{N}$-terminal substrate recognition domain of FimD $\left(\right.$ FimD $\left._{N}\right)$ before and after binding of a chaperone-subunit complex. FimD $\mathrm{D}_{\mathrm{N}}$ consists of a flexible $\mathrm{N}$-terminal segment of 24 residues, a structured core with a novel fold, and a $\mathrm{C}$-terminal hinge segment. In the ternary complex, residues 1-24 of $\mathrm{FimD}_{\mathrm{N}}$ specifically interact with both FimC and the subunit, acting as a sensor for loaded FimC molecules. Together with in vivo complementation studies, we show how this mechanism enables recognition and discrimination of different chaperonesubunit complexes by bacterial pilus assembly platforms. The EMBO Journal (2005) 24, 2075-2086. doi:10.1038/

sj.emboj.7600693; Published online 26 May 2005

Subject Categories: structural biology; microbiology

\& pathogens

Keywords: chaperone-usher pathway; Escherichia coli; FimD; protein structure; type 1 pili

\section{Introduction}

A wide variety of pathogenic bacteria possess adhesive surface organelles ('pili') that mediate binding to host tissue. These highly oligomeric, filamentous protein complexes are

\footnotetext{
*Corresponding authors. R Glockshuber, Institut für Molekularbiologie und Biophysik, Eidgenössische Technische Hochschule Hönggerberg, 8093 Zürich, Switzerland. Tel.: +411633 6819;

Fax: + 411633 1036; E-mail: rudi@mol.biol.ethz.ch or G Capitani, Biochemisches Institut, Universität Zürich, Winterthurerstrasse 190, 8057 Zürich, Switzerland. Tel.: + 411635 5587;

Fax: + 411635 6834; E-mail: capitani@bioc.unizh.ch

${ }^{3}$ Present address: Department of Molecular Biology, The Scripps Research Institute, 10550 North Torrey Pines Road, La Jolla, CA 92037, USA
}

Received: 23 March 2005; accepted: 3 May 2005; published online: 26 May 2005 anchored to the outer bacterial membrane (Jones et al, 1995). Type 1 pili from uropathogenic Escherichia coli strains are required for bacterial attachment to mannose units of the glycoprotein receptor uroplakin Ia on the surface of urinary epithelium cells, and thus mediate the first critical step in the infection process (Mulvey et al, 1998; Zhou et al, 2001). In addition, type 1 pili are responsible for bacterial invasion and persistence in target cells (Baorto et al, 1997; Martinez et al, 2000). The quaternary structure of type 1 pili is characterized by a 6.9-nm wide pilus rod consisting of a right-handed, helical array of 500-3000 copies of the most abundant structural subunit FimA, and a linear tip fibrillum composed of the adhesin FimH and several copies of the subunits FimG and FimF (Jones et al, 1995; Hahn et al, 2002) (Figure 1).

Biogenesis of type 1 pili is governed by the chaperoneusher pathway (Thanassi and Hultgren, 2000; Sauer et al, 2004). The assembly machinery is composed of two specialized classes of proteins: a periplasmic chaperone and an outer membrane assembly platform, which is also referred to as the usher. The periplasmic type 1 pilus chaperone FimC forms stoichiometric complexes with pilus subunits, catalyzes their folding, and transports them to the assembly platform FimD in the outer membrane (Jones et al, 1993; Vetsch et al, 2004) (Figure 1). The X-ray structure of the FimC-FimH complex (Choudhury et al, 1999) as well as the structures of the related chaperone-subunit complexes PapDPapK (Sauer et al, 1999), PapD-PapE (Sauer et al, 2002), and Caf1M-Caf1 (Zavialov et al, 2003) have shown that pilus subunits have an incomplete immunoglobulin-like fold that lacks the seventh, C-terminal $\beta$-strand (referred to hereafter as 'pilin fold'). In chaperone-subunit complexes, the missing $\beta$-strand is provided by a polypeptide segment of the chaperone, the 'donor strand', which is inserted parallel to the sixth strand of the subunit (Choudhury et al, 1999; Sauer et al, 1999, 2002; Zavialov et al, 2003). In the assembled pilus, an $\mathrm{N}$-terminal extension of about 15 residues, preceding the pilin fold, acts as the donor strand and complements the pilin fold of the adjacent pilus subunit (Sauer et al, 2002; Zavialov et al, 2003). In this way, each subunit provides its own donor strand to the preceding subunit and accepts a donor strand from the following subunit. In contrast to the chaperonesubunit complexes, the orientation of the inserted donor strand in the pilus is antiparallel to the sixth $\beta$-strand of the preceding subunit. Structure comparison of a chaperonebound subunit and the same subunit in complex with another subunit indicates that a conformational transition of the pilin fold occurs upon exchange of the donor strand during subunit assembly (Sauer et al, 2002; Zavialov et al, 2003). It has been proposed that this conformational change is the driving force for pilus assembly (Sauer et al, 2002; Zavialov et al, 2003). This hypothesis is further supported by the observations that pilus assembly is independent of ATP and of an electrochemical gradient (Jacob-Dubuisson et al, 1994), and that 


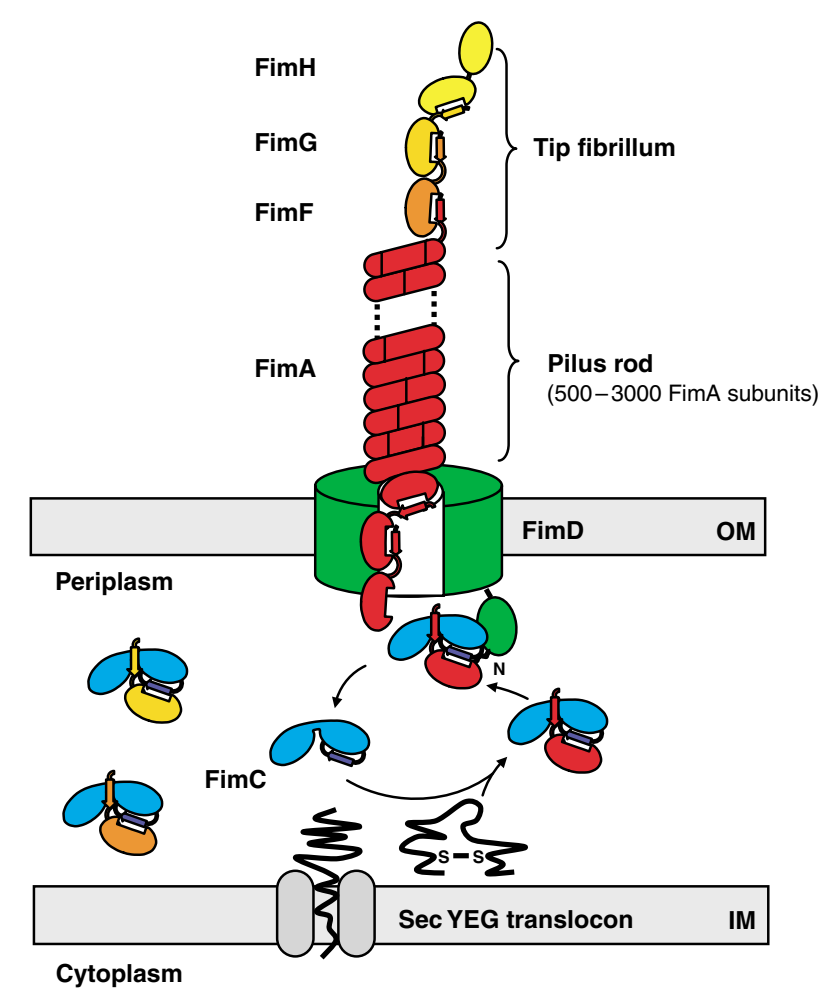

Figure 1 Schematic model of type 1 pilus assembly by the chaperone-usher pathway. The periplasmic chaperone FimC forms stoichiometric complexes with the newly translocated pilus subunits (FimA, FimG, FimF, FimH). In these complexes, FimC donates its $\mathrm{G}_{1}$ donor strand to the individual subunits, thereby completing the immunoglobulin-like fold of the subunits. FimC-subunit complexes diffuse to the assembly platform (usher) FimD, which specifically recognizes FimC-subunit complexes via its periplasmic, N-terminal segment of residues 1-139. Subsequently, FimC is released to the periplasm, and the subunit is delivered to the translocation pore of FimD, where it is supposed to interact with the previously incorporated subunit via donor strand exchange. The pilus rod, composed of FimA subunits, assembles into its helical quaternary structure on the cell surface. IM, inner membrane; OM, outer membrane.

subunit-subunit complexes are thermodynamically more stable than chaperone-subunit complexes (Vetsch et al, 2004).

The type 1 pilus assembly platform FimD is a multifunctional outer membrane protein of 833 residues (Klemm and Christiansen, 1990), which not only anchors the pilus to the cell surface but also recognizes FimC-subunit complexes in the periplasm and mediates translocation of folded subunits through the outer membrane (Saulino et al, 1998, 2000). In spite of the fundamental role of assembly platforms in pilus biogenesis, no structural information on the atomic level is available to date. Based on electron microscopy data on its $P$ pilus homologue PapC, FimD is supposed to form a pore of about $2 \mathrm{~nm}$ diameter into the outer membrane (Saulino et al, 2000; Li et al, 2004). This pore size would be wide enough for translocation of individual folded subunits from the periplasm to the cell surface, but not for translocation of the helical pilus rod, which appears to attain its final quaternary structure only on the cell surface (Bullitt and Makowski, 1995).

In a previous study, we showed that FimD possesses an $\mathrm{N}$-terminal periplasmic domain, FimD $_{\mathrm{N}}$, comprising residues $1-139$. FimD $\mathrm{D}_{\mathrm{N}}$ is soluble in the absence of detergents, folds autonomously, and specifically binds FimC-subunit com- plexes with micromolar affinities although FimC or pilus subunits alone are not recognized (Nishiyama et al, 2003). In accordance with these data, the recognition site of chaperone-subunit complexes in PapC was also localized to the $\mathrm{N}$-terminal 124 residues ( $\mathrm{Ng}$ et al, 2004). Nevertheless, it has been discussed controversially whether the N-terminal chaperone-subunit-binding region of pilus assembly platforms is an independent periplasmic domain (Harms et al, 1999; Nishiyama et al, 2003), or belongs to the porin-like $\beta$-barrel transmembrane domain of FimD (Henderson et al, 2004; $\mathrm{Ng}$ et al, 2004).

Here we report nuclear magnetic resonance (NMR) and $\mathrm{X}$-ray protein structures that provide snapshots of the initial step of pilus formation at the site of the assembly platform, that is, the chaperone-subunit recognition domain of an assembly platform before and after binding of a chaperonesubunit complex. The NMR structure of isolated FimD $_{\mathrm{N}}$ reveals that this domain consists of a flexible, N-terminal 'tail' (residues 1-24), a structured 'core' (residues 25-125) with a novel polypeptide fold, and a potential hinge segment (residues 126-135) that connects the structured core to the transmembrane region of FimD. The most remarkable feature of FimD $_{\mathrm{N}}$ is its flexible N-terminal tail, which adopts a defined conformation only upon binding to the complex between FimC and the pilin domain of FimH $\left(\right.$ FimH $_{\mathrm{P}}$, residues 158-279 of FimH), as revealed by the $1.8 \AA$ crystal structure of the ternary FimD ${ }_{N}-$ FimC-FimH $H_{P}$ complex. The structural data, in conjunction with biochemical experiments and in vivo complementation studies, suggest a mechanism in which the assembly platform utilizes its flexible N-terminal segment 1-24 to accomplish specific recognition of different chaperone-subunit complexes.

\section{Results and discussion}

\section{The NMR solution structure of free Fim $D_{N}$ reveals a previously unknown fold with mobile chain ends}

Initial NMR experiments with $\operatorname{FimD}_{\mathrm{N}}(1-139)$ (residues 1-139 of FimD) showed that this construct is susceptible to $\mathrm{N}$-terminal degradation when incubated for several days at $25^{\circ} \mathrm{C}$ and at a concentration of $1 \mathrm{mM}$, most likely due to minute protease contaminations. Edman sequencing and mass spectrometry revealed nonspecific N-terminal degradation of FimD $_{N}(1-139)$ with cleavage after residues Leu9, Ala10, Gln13, and Ser20 (data not shown). Moreover, measurement of $\left[{ }^{15} \mathrm{~N},{ }^{1} \mathrm{H}\right] \mathrm{NOEs}$ showed that the segment $1-24$ of the polypeptide chain is flexibly disordered (Supplementary Figure S1). We then incubated the ternary complex formed by FimD $_{\mathrm{N}}(1-139)$, FimC, and the pilin domain of FimH $\left(\right.$ FimH $\left._{\mathrm{P}}\right)$ under identical conditions. In the complex, we observed specific and quantitative cleavage of FimD $_{\mathrm{N}}(1-139)$ at a single site close to the C-terminus (Ala125), but no $\mathrm{N}$-terminal degradation was observed. Comparison of the thermal stabilities of FimD $_{\mathrm{N}}(1-139)$ and its truncated variants FimD $_{\mathrm{N}}$ (25-139) and FimD $\mathrm{N}_{\mathrm{N}}(1-125)$ at $\mathrm{pH} 7.4$, which were monitored by the far-UV circular dichroism signal at $218 \mathrm{~nm}$, showed identical transition midpoints $\left(T_{\mathrm{m}}\right)$ of $67.6 \pm 0.5^{\circ} \mathrm{C}$ for all the constructs (Supplementary Table S1). Combined with the aforementioned NMR data, the thermal denaturation data show that the segment $25-125$ of $\operatorname{FimD}_{\mathrm{N}}(1-139)$ adopts a stable tertiary structure, independent of whether or not the terminal chain segments are present. 
Based on these data, we decided to perform a NMR structure determination of the $\mathrm{N}$ - and C-terminally truncated protein fragment FimD $\mathrm{D}_{\mathrm{N}}(25-125)$ (Figure 2A and B; Table I). The scaffold of the tertiary structure is formed by a threestranded, antiparallel $\beta$-sheet $\left(\beta_{1}-\beta_{3}\right)$ consisting of residues $31-39,42-53$, and $60-62$, and a two-stranded, antiparallel $\beta$ sheet $\left(\beta_{4}\right.$ and $\left.\beta_{5}\right)$ comprising residues $101-105$ and 110-114, respectively. The two $\beta$-sheets are connected by a peptide segment comprising a single-turn $3_{10}$-helix (residues 76-78), and the $\alpha$-helices $\alpha_{1}$ (residues 66-72) and $\alpha_{2}$ (residues 93-96). The invariant cysteine pair (Cys63 and Cys90; cf. Figure 4) forms a disulfide bond stabilizing this peptide segment. A second $33_{10}$-helix (residues 117-119) is located close to the C-terminus. The helices $\alpha_{1}$ and $\alpha_{2}$ are packed tightly against the $\beta$-sheets, with Met72 of $\alpha_{1}$ in direct contact with Met44 and Leu39 of $\beta_{2}$ and Leu113 of $\beta_{5}$, and Leu93 of $\alpha_{2}$ in contact with Ala102 of $\beta_{4}$ and Leu113 of $\beta_{5}$. The helices $\alpha_{1}$ and $\alpha_{2}$ pack at an angle of $50^{\circ}$ to each other, with pronounced hydrophobic interactions between Leu69 and Leu93. A comparison of the structure of $\mathrm{FimD}_{\mathrm{N}}(25-125)$ with the structures deposited in the Protein Data Bank (PDB) (Berman et al, 2000) using the DALI server (Holm and Sander, 1998) identified no structural homologues. The two structurally most closely related proteins, PDB entries $1 \mathrm{SFO}$ and 1T0Y, exhibited $Z$-scores of 2.1 and 2.0, respectively, with r.m.s.d. values for the $\mathrm{C}^{\alpha}$ atoms of 3.8 and $3.6 \AA$ over 51 and 58 aligned residues, respectively. This shows that FimD $_{N}(25-125)$ represents a previously unknown polypeptide fold. In addition, the NMR data confirm that FimD $_{\mathrm{N}}(25-125)$ forms a self-folding periplasmic domain that precedes the transmembrane domain of FimD, and they are in clear-cut contrast with models predicting that the $\mathrm{N}$-terminal region of the assembly platform belongs to the $\beta$-barrel transmembrane domain (Henderson et al, 2004; Ng et al, 2004).

In order to study the role of the segment 126-139, which is supposed to connect FimD $_{\mathrm{N}}(25-125)$ to the transmembrane domain of FimD (according to a topology prediction program by Martelli et al (2002), residue 138 is the first residue of a transmembrane $\beta$-barrel of FimD), we further solved the NMR structure of FimD $_{N}(25-139)$ (Figure 2C). Except for the additional C-terminal residues, the structure of $\mathrm{FimD}_{\mathrm{N}}(25-$ $139)$ is in very close agreement with that of FimD $_{N}(25-125)$, with an r.m.s.d. of $1.0 \AA$ for the $\mathrm{C}^{\alpha}$ atoms of the residues $30-120$. Interestingly, the segment $126-135$ is not disordered in FimD $_{\mathrm{N}}(25-139)$, even though it does not adopt a regular secondary structure (Figure $2 \mathrm{C}$ ). Although the residues 136-139 show negative $\left[{ }^{15} \mathrm{~N},{ }^{1} \mathrm{H}\right] \mathrm{NOE}$ values indicative of high-frequency internal motions, those of the residues 121-135 are positive, suggesting rotational tumbling with an effective rotational correlation time similar to that for overall tumbling of the globular domain (Supplementary Figure S1). In addition, we identified a network of longrange NOEs connecting side-chain protons of Trp133 with Val49, Leu64, Thr65, Gln68, and Met72 of the globular domain. These NOEs define a unique position of the aromatic ring of Trp133 in a binding pocket on the surface of the folded domain FimD $_{\mathrm{N}}(25-125)$ (Figure 2D). We interpret these observations in terms of a rapid, intramolecular association/ dissociation equilibrium between the domain FimD $_{N}(25-125)$ and the segment 126-135. The fact that $\operatorname{FimD}_{\mathrm{N}}(25-139)$ and FimD $_{N}(25-125)$ have identical $T_{m}$ values indicates that the Cterminal segment 126-135 dissociates in a spectroscopically silent fashion from the folded core of FimD $_{\mathrm{N}}$, presumably at a temperature below the observed $T_{\mathrm{m}}$ value (Supplementary Table S1). As will be discussed below, there are indications that the intramolecular association/dissociation equilibrium between the domain FimD $_{\mathrm{N}}(25-125)$ and the polypeptide segment 126-135 might be related to a spatial rearrangement of residues 1-125 relative to the transmembrane domain of FimD when chaperone-subunit complexes are bound.

\section{$X$-ray structure determination of the $\operatorname{Fim}_{N}(1-125)-$ FimC-Fim $H_{P}$ ternary complex}

The search for optimal crystallization conditions of a ternary complex between FimD $_{\mathrm{N}}$, FimC, and a bound pilus subunit led us to use protein constructs without disordered segments that might impair crystallization. We therefore investigated the requirement of the flexible segment $1-24$ and the C-terminal region 126-139 of FimD for the recognition of FimC-subunit complexes. In addition, we used the C-terminal pilin domain of FimH (FimH , residues 158-279 of FimH) instead of full-length FimH, because the structure of the FimC-FimH complex (Choudhury et al, 1999) had revealed that FimC interacts exclusively with $\mathrm{FimH}_{\mathrm{P}}$. Moreover, the interaction between FimC and $\mathrm{FimH}_{\mathrm{P}}$ through donor strand complementation is representative for all FimC-pilus subunit complexes (Choudhury et al, 1999), and the lectin domain is not required for recognition of the FimC-FimH complex by FimD $_{\mathrm{N}}(1-139)$ (Nishiyama et al, 2003). Taking these facts into account, we tested the ability of the truncated

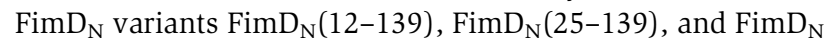
(1-125) to bind the FimC-FimH $H_{P}$ complex in vitro. Analytical gel filtration revealed that residues 1-24 are strictly required for the formation of the FimD $_{N}-$ FimC-FimH $H_{P}$ ternary complex (Figure 5B), although they are disordered in the NMR structure of isolated FimD $_{N}(1-139)$ (Supplementary Figure S1). The requirement of segment 1-24 was confirmed by the observation that deletion of residues 1-12 or residues 1-24 in full-length FimD completely abolished the ability of plasmid-encoded FimD to restore type 1 pilus formation in an E. coli fimD deletion strain (W3110 $\Delta$ fimD) (Figure 5A). In contrast, residues $126-139$ in FimD $_{\mathrm{N}}$ are not needed for the formation of the ternary complex in vitro, since the variant FimD $_{\mathrm{N}}(1-125)$ exhibits the same affinity towards the FimC$\mathrm{FimH}_{\mathrm{P}}$ complex as full-length $\mathrm{FimD}_{\mathrm{N}}(1-139)$ (Supplementary Table S2).

Based on these results, we crystallized the ternary complex between FimD $_{\mathrm{N}}(1-125)$, FimC, and $\mathrm{FimH}_{\mathrm{P}}$, and obtained two different crystal forms, $\mathrm{A}$ and $\mathrm{B}$, with space groups $\mathrm{P}_{3}$ and $\mathrm{P} 2_{1} 2_{1} 2_{1}$, respectively. The structure of the ternary complex was solved with data collected from a single crystal of form $B$ at $1.8 \AA$ resolution through molecular replacement based on the structure of the FimC-FimH complex (Choudhury et al, 1999). Structure refinement resulted in $R$-factor and free $R$-factor values of 0.19 and 0.22 , respectively (Table II). The final model encompasses residues 1-205 of FimC, residues 158-279 of FimH $_{\mathrm{P}}$, and residues 1-9 and 19-125 of FimD $_{\mathrm{N}}$ (1-125) (Figure 3). Residues 10-18 of FimD $_{N}(1-125)$ were not included in the model due to missing electron density. The lack of electron density in this region was confirmed by computation of a simulated-annealing omit map. As the FimD $_{\mathrm{N}}$ segment $10-18$ is also disordered in the electron density map obtained from crystal form A, the lack of density in this region appears to be an intrinsic property of the 
A

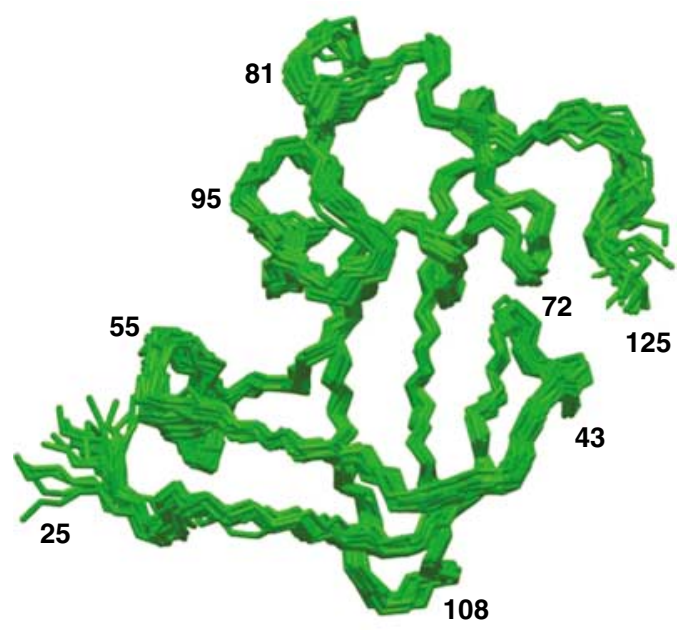

C

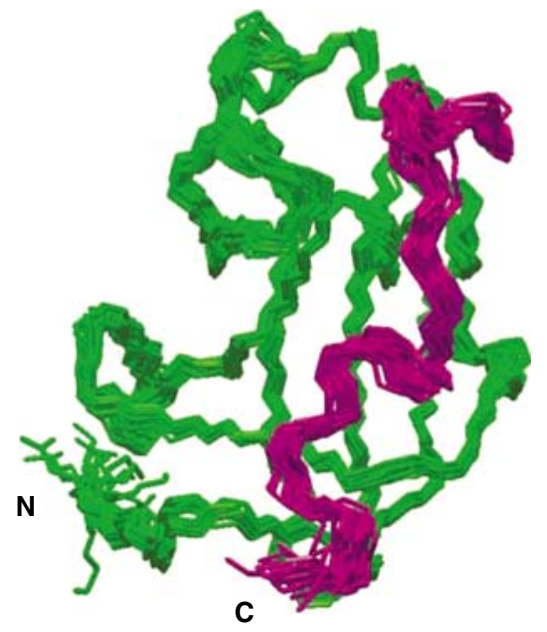

\section{E}

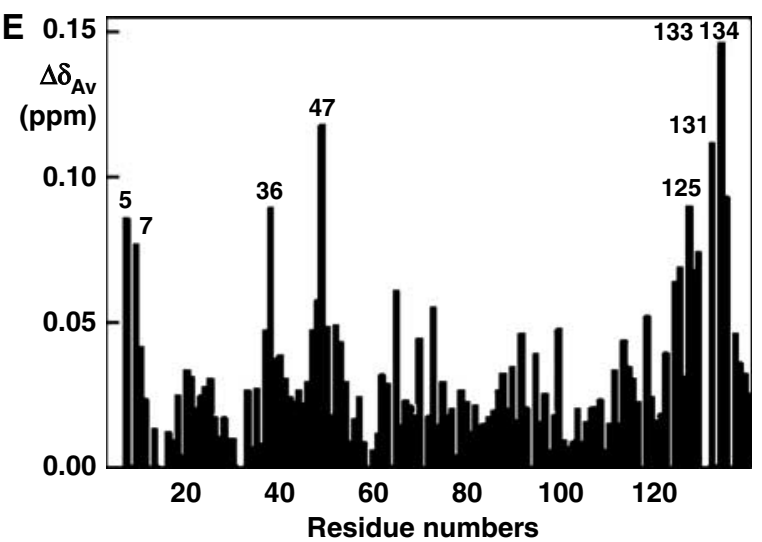

B

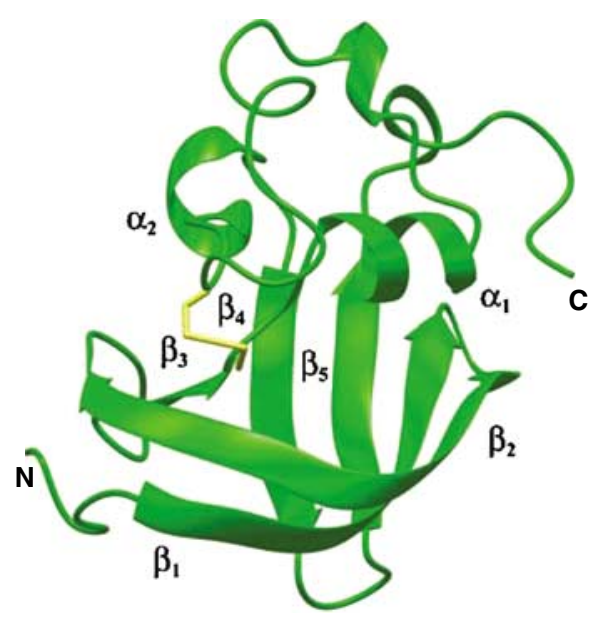

D

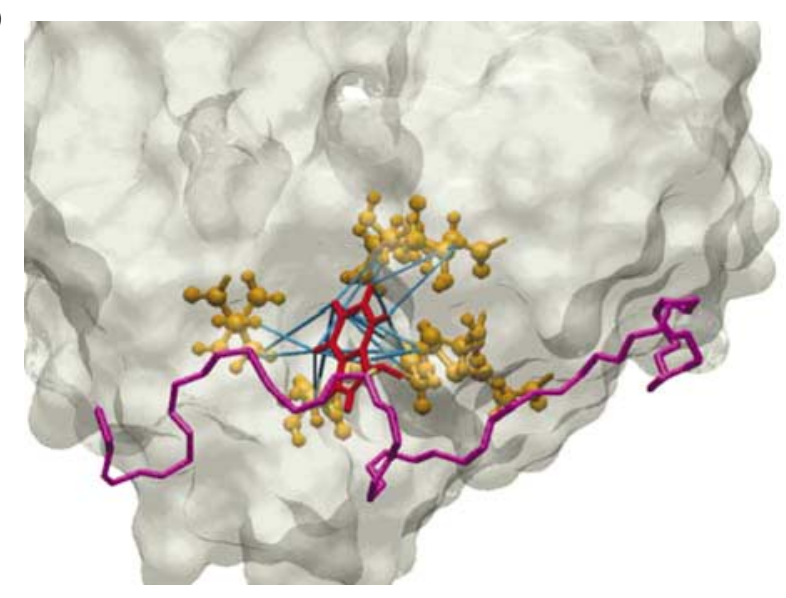

$\mathbf{F}$

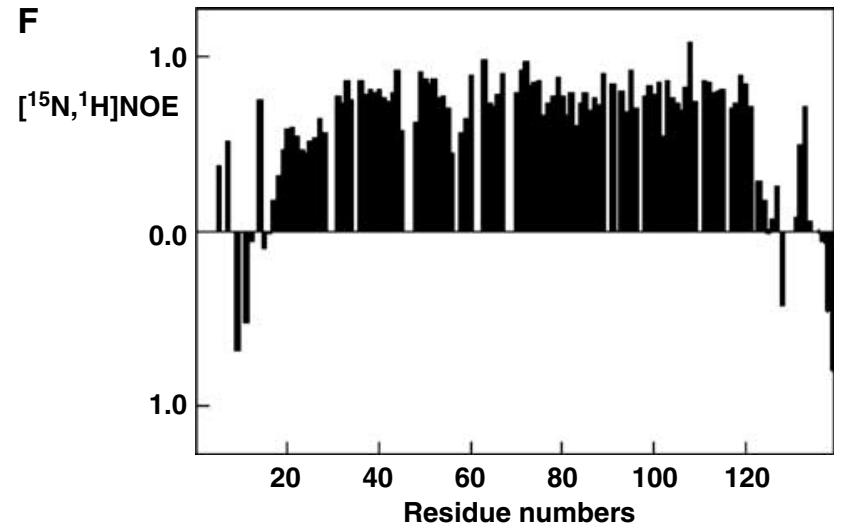

Figure 2 NMR studies on FimD $D_{N}$. (A) Polypeptide backbone of FimD $\mathrm{N}_{\mathrm{N}}(25-125)$ represented by a bundle of 20 energy-minimized DYANA conformers. Selected positions along the polypeptide chain are identified with sequence positions. (B) Ribbon drawing of one of the 20 energyminimized conformers. $\beta_{1}-\beta_{5}$ and $\alpha_{1}-\alpha_{2}$ indicate five $\beta$-strands and two $\alpha$-helices, respectively. The disulfide bridge Cys63-Cys 90 is drawn in yellow. The chain ends are identified by the letters $\mathrm{N}$ and $\mathrm{C}$. (C) NMR structure of $\operatorname{FimD}_{\mathrm{N}}(25-139)$ represented by a bundle of 20 energyminimized DYANA conformers showing only the polypeptide backbone. The chain ends are identified by the letters $\mathrm{N}$ and $\mathrm{C}$. The C-terminal residues 125-139 are shown in magenta. (D) Close-up view of the surface of one of the 20 energy-minimized conformers of FimD $\mathrm{N}_{\mathrm{N}}(25-139)$. Relative to (C), the structure has been rotated by approximately $90^{\circ}$ about a vertical axis. The backbone of the C-terminal stretch $125-139$ is drawn in magenta, and the side chain of Trp133 is indicated in red. Those side chains which show long-range NOE connectivities with Trp133 are drawn in bronze. In total, 14 long-range upper-distance limits between Trp133 and the rest of the protein (shown in cyan) define the position of the aromatic ring of Trp133. (E) Chemical shift variations of FimD $D_{\mathrm{N}}$ upon binding to FimC-FimH. $\Delta \delta_{\mathrm{Av}}$ is the weighted average of the ${ }^{15} \mathrm{~N}$ and ${ }^{1} \mathrm{H}$ chemical shifts, $\Delta \delta_{A v}=\sqrt{0.5\left(\Delta \delta_{H}^{2}+0.2 \Delta \delta_{N}^{2}\right)}$ (Pellecchia et al, 1999). (F) Heteronuclear $\left[{ }^{15} \mathrm{~N},{ }^{1} \mathrm{H}\right] \mathrm{NOE}$ measurements of FimD $_{\mathrm{N}}(1-139)$ in the FimD $\mathrm{N}_{\mathrm{N}}$-FimC-FimH $\mathrm{P}_{\mathrm{P}}$ ternary complex. Values between 0.5 and 1 indicate well-structured parts of the protein; values $<0.5$ manifest increased flexibility. 
Table I Input for the structure calculation and characterization of the energy-minimized NMR structures of FimD $D_{N}(25-139)$ and FimD $(25-$ 125)

\begin{tabular}{|c|c|c|}
\hline Quantity $^{\mathrm{a}}$ & $\operatorname{FimD}_{\mathrm{N}}(25-139)$ & $\operatorname{FimD}_{N}(25-125)$ \\
\hline NOE upper distance limits & 2928 & 2953 \\
\hline Dihedral angle constraints & 94 & 94 \\
\hline Residual target function $\left(\AA^{2}\right)$ & $1.57 \pm 0.33$ & $1.20 \pm 0.43$ \\
\hline \multicolumn{3}{|l|}{ Residual NOE violations } \\
\hline Number $\geqslant 0.1 \AA$ & $31 \pm 6(24-45)$ & $22 \pm 5(5-29)$ \\
\hline Maximum $(\AA)$ & $0.14 \pm 0.01(0.12-0.15)$ & $0.14 \pm 0.01(0.12-0.17)$ \\
\hline \multicolumn{3}{|l|}{ Residual dihedral angle violations } \\
\hline Number $\geqslant 2.5 \mathrm{deg}$ & $0 \pm 1(0-2)$ & $1 \pm 1(0-3)$ \\
\hline Maximum (deg) & $1.82 \pm 1.12(0.35-4.54)$ & $2.89 \pm 1.32(1.57-7.44)$ \\
\hline \multicolumn{3}{|l|}{ Amber energies $(\mathrm{kcal} / \mathrm{mol})$} \\
\hline Total & $-4323.89 \pm 76.56$ & $-4129.35 \pm 55.45$ \\
\hline Van der Waals & $-327.64 \pm 13.24$ & $-292.04 \pm 16.14$ \\
\hline Electrostatic & $-4948.89 \pm 74.37$ & $-4673.08 \pm 52.16$ \\
\hline \multicolumn{3}{|l|}{ R.m.s.d. from ideal geometry } \\
\hline Bond lengths $(\AA)$ & $0.0078 \pm 0.0001$ & $0.0079 \pm 0.0002$ \\
\hline Bond angles (deg) & $2.035 \pm 0.044$ & $2.022 \pm 0.067$ \\
\hline \multicolumn{3}{|l|}{ R.m.s.d. to the mean coordinates $\left(A^{\circ}\right)$} \\
\hline bb (35-120) & $0.43 \pm 0.06(0.33-0.54)$ & $0.40 \pm 0.06(0.28-0.54)$ \\
\hline ha $(35-120)$ & $0.74 \pm 0.07(0.62-0.95)$ & $0.74 \pm 0.06(0.67-0.90)$ \\
\hline \multicolumn{3}{|l|}{ Ramachandran plot statistics ${ }^{\mathrm{c}}$} \\
\hline Most favored regions (\%) & 72 & 71 \\
\hline Additional allowed regions (\%) & 25 & 26 \\
\hline Generously allowed regions (\%) & 2 & 2 \\
\hline Disallowed regions (\%) & 1 & 1 \\
\hline
\end{tabular}

${ }^{a}$ Except for the three top entries, the average value for the 20 energy-minimized conformers with the lowest residual DYANA target function values and the standard deviation among them are given. For the residual violations and the r.m.s.d. values, the range from the minimum to the maximum value is given in parentheses.

bb indicates the backbone atoms $\mathrm{N}, \mathrm{C}^{\alpha}, \mathrm{C}^{\gamma}$; ha stands for 'all heavy atoms'. The numbers in parentheses indicate the residues for which the r.m.s.d. was calculated.

${ }^{\mathrm{c}}$ As determined by PROCHECK (Laskowski et al, 1993).

Table II Summary of crystallographic data collection and refinement statistics

\begin{tabular}{|c|c|}
\hline \multicolumn{2}{|l|}{ Data collection } \\
\hline Radiation source & SLS Villigen, CH beamline X06SA \\
\hline Wavelength $(\AA)$ & 0.900 \\
\hline Space group & $\mathrm{P} 2_{1} 2_{1} 2_{1}$ \\
\hline Unit cell & $a=54.82 \AA, b=83.32 \AA, c=110.23 \AA$ \\
\hline Resolution range $(\AA)$ & $33.7-1.84$ \\
\hline No. of reflections & 284810 \\
\hline No. of unique reflections & 44185 \\
\hline Redundancy & 6.4 \\
\hline Completeness (\%) & $99.9(99.5)^{\mathrm{a}}$ \\
\hline$R_{\text {sym }}(\%)$ & $8.8(36.3)^{\mathrm{a}}$ \\
\hline Average $I / \sigma$ & $15.0(3.1)^{\mathrm{a}}$ \\
\hline \multicolumn{2}{|l|}{ Refinement } \\
\hline Resolution $(\AA)$ & $33.7-1.84$ \\
\hline No. of reflections (test) & $44185(895)$ \\
\hline \multicolumn{2}{|l|}{ No. of atoms } \\
\hline Protein & 3375 \\
\hline Ligands (ethylene glycole) & 48 \\
\hline Water molecules & 510 \\
\hline \multicolumn{2}{|l|}{ Ramachandran plot (\%) } \\
\hline Most favored & 92.8 \\
\hline Additional allowed & 7.2 \\
\hline$R$-factor & $0.190(0.247)^{\mathrm{a}}$ \\
\hline Free $R$-factor & $0.216(0.266)^{\mathrm{a}}$ \\
\hline R.m.s.d. bonds $(\AA)$ & 0.005 \\
\hline R.m.s.d. angles (deg) & 1.33 \\
\hline Average $B$-factor $\left(\AA^{2}\right)$ & 18.8 \\
\hline
\end{tabular}

aLast shell: $1.91-1.84 \AA$.
FimD $_{\mathrm{N}}-$ FimC-FimH $\mathrm{P}_{\mathrm{P}}$ complex. The nature of the structural disorder was further investigated by measurements of heteronuclear $\left[{ }^{15} \mathrm{~N},{ }^{1} \mathrm{H}\right] \mathrm{NOEs}$ for FimD $_{\mathrm{N}}$ in the ternary complex (Figure $2 \mathrm{~F}$ ), which showed that the effective rotational correlation time of the residues $10-18$ is significantly shorter than that for the structured parts of the protein. Interestingly, the residues Asn5 and Arg7 have positive $\left[{ }^{15} \mathrm{~N},{ }^{1} \mathrm{H}\right] \mathrm{NOE}$ values, which is an indication that these residues get immobilized upon complex formation.

\section{Both the N-terminal tail 1-24 and the structured core 25-125 of FimD $D_{N}$ contribute to recognition of FimC-subunit complexes}

The crystal structure of the FimD $_{\mathrm{N}}-$ FimC-FimH $\mathrm{P}_{\mathrm{P}}$ complex reveals a unique mechanism for recognition of the chaperone-subunit complex by the bacterial pilus assembly platform. FimC interacts via its N-terminal domain (residues 1116) with both the pilin domain of FimH, through donor strand complementation, and with the globular core of FimD $_{N}$ (residues 25-125). The FimD $D_{N}$ core thereby forms no direct contacts with the pilin domain (Figure $3 \mathrm{~A}$ ). Comparison of the NMR structure of isolated FimD $_{\mathrm{N}}(25-$ $125)$ and the crystal structure of FimD $_{N}(1-125)$ in the ternary complex reveals that the core of FimD $_{N}$ does not undergo significant conformational changes upon binding to the FimC-FimH $H_{P}$ complex (r.m.s.d. $=1.2 \AA$ for the $\mathrm{C}^{\alpha}$ atoms of 
A

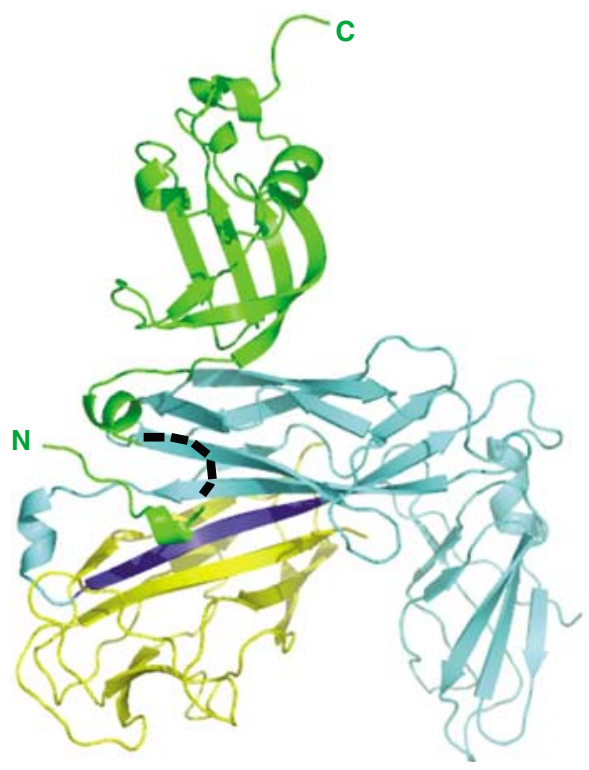

B

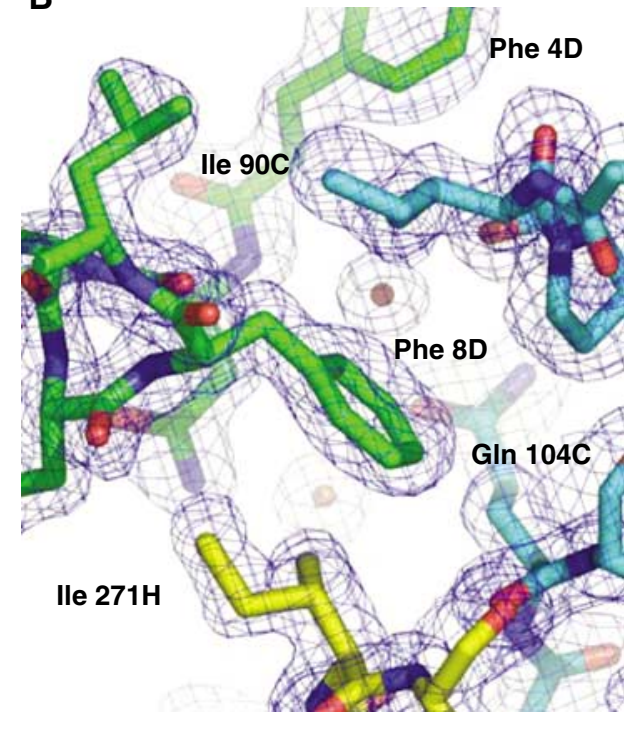

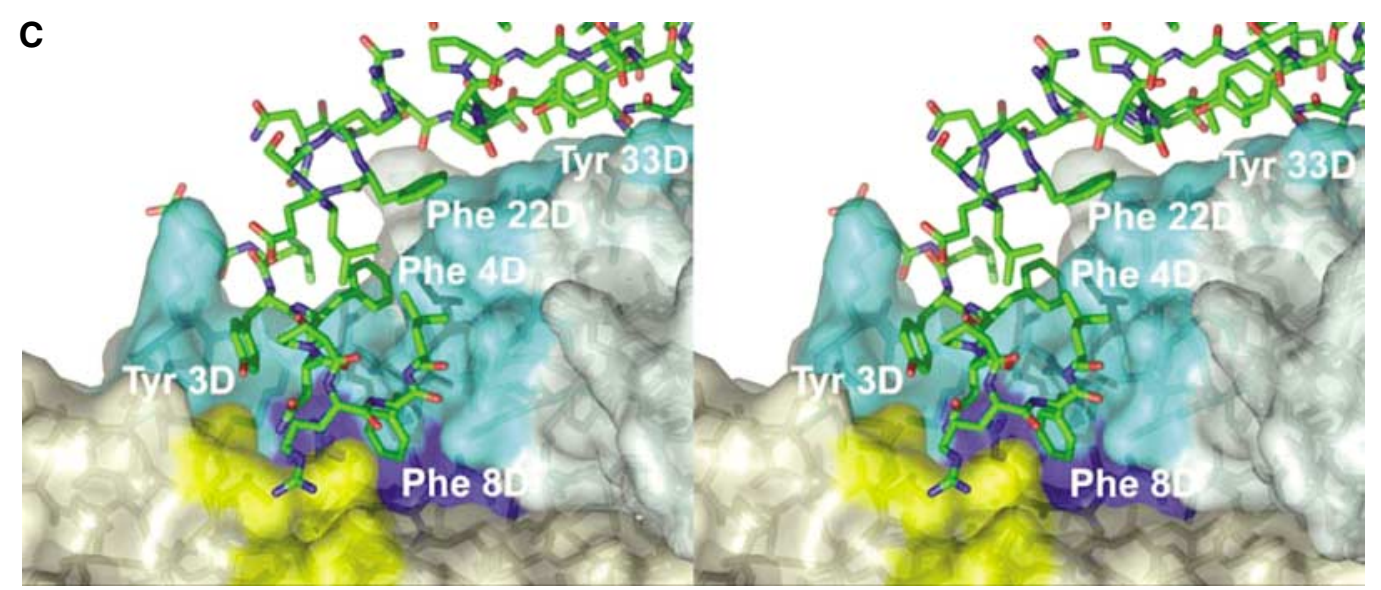

D
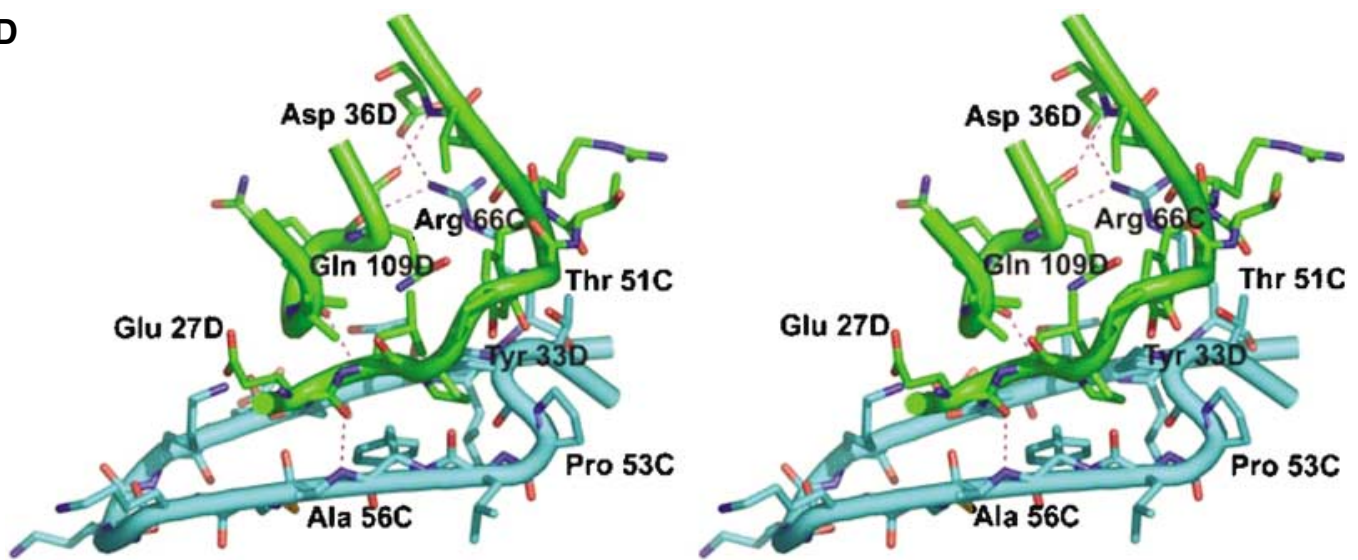

Figure 3 X-ray structure of the ternary FimD $\mathrm{N}_{\mathrm{N}}(1-125)-$ FimC-FimH $\mathrm{P}_{\mathrm{P}}$ complex. (A) Ribbon diagram of the ternary complex, with FimD $\mathrm{N}_{\mathrm{N}}(1-125)$ depicted in green, FimC in cyan and the pilin domain $\mathrm{FimH}_{\mathrm{P}}$ in yellow. The $\mathrm{G}_{1}$ donor strand of FimC is colored in blue. A black dashed line indicates residues 10-18 of $\mathrm{FimD}_{\mathrm{N}}$, for which no electron density was observed. The $\mathrm{N}$ - and C-termini of FimD $\mathrm{N}_{\mathrm{N}}$ are labeled in green. (B) Closeup view of the hydrophobic contacts between Phe8 of the N-terminal FimD $D_{\mathrm{N}}$ tail (green) and residues from FimC (cyan) and FimH $\mathrm{H}_{\mathrm{p}}$ (yellow). The final $2 \mathrm{mFo}-\mathrm{DFc}$ electron density map is contoured at $1 \sigma$ level. (C) Stereo representation of the tail interface. Residues from FimD $\mathrm{N}_{\mathrm{N}}$, in stick model, are shown in green. The molecular surfaces of FimC (slate-grey) and $\mathrm{FimH}_{\mathrm{P}}$ (light yellow) are shown in semitransparent mode. Residues contributing to the FimC and $\mathrm{FimH}_{\mathrm{P}}$ surfaces and interacting with FimD $\mathrm{N}_{\mathrm{N}}$ are shown in more intense color: cyan for FimC and yellow for FimH $H_{P}$ residues, respectively. Residues from the $G_{1}$ donor strand of FimC contributing to the molecular surface appear in blue. (D) Stereo representation of the interface between FimC and the folded FimD $\mathrm{N}_{\mathrm{N}}$ core $25-125$. Some hydrogen bonds between FimC and the FimD $\mathrm{D}_{\mathrm{N}}$ core are depicted as thin dashed lines. Color coding is as in (A). The figure was prepared with Pymol (www.pymol.org). 
residues 28-121) (Supplementary Figure S2A). Moreover, the structures of FimC and FimH $_{P}$ in the ternary complex are closely similar to those in the previously published FimCFimH binary complex, with some local differences (see Supplementary data). Importantly, the residues 1-24 of the N-terminal 'tail', which are completely unstructured in free FimD $_{N}$, become ordered upon complex formation and specifically interact with both FimC and the bound pilin domain (Figure 3A). The interactions formed by the $\mathrm{N}$-terminal FimD $_{N}$ tail comprise $60 \%$ of the total interface area of $1260 \AA^{2}$ between FimD $_{N}(1-125)$ and the FimC-FimH $H_{P}$ complex. The other $40 \%$ of the contact area is contributed by the folded core FimD $D_{N}(25-125)$, which exhibits a complementary surface to FimC. The total interface area of FimD $_{N}(1-125)$ in the ternary complex is in good agreement with the average value of $1210 \AA^{2}$ that was calculated for a set of proteinprotein complexes with dissociation constants in the micromolar range (Nooren and Thornton, 2003) $\left(K_{\mathrm{D}}=1.2 \mu \mathrm{M}\right.$ for the interaction between FimD $_{\mathrm{N}}$ and the FimC-FimH $\mathrm{P}_{\mathrm{P}}$ complex (Nishiyama et al, 2003)).

The N-terminal tail 1-24 of $\mathrm{FimD}_{\mathrm{N}}$ thus serves as a sensor that selectively detects loaded FimC molecules. As the tail is the only FimD $_{\mathrm{N}}$ region that forms contacts with the chaperone-bound subunit, it may be exclusively responsible for the discrimination of the different FimC-subunit complexes by the assembly platform (Saulino et al, 1998). FimD binds to different FimC-subunit complexes with different affinities, which is a key element for correct initiation of pilus assembly and for the correct ordering of the subunit incorporation into the pilus (Saulino et al, 1998; Nishiyama et al, 2003). In the case of the FimC-FimH complex, which is bound by FimD with highest affinity (Saulino et al, 1998), additional contacts between the FimH lectin domain and other FimD regions could contribute to binding, as FimD has been shown to recognize the isolated FimH lectin domain (Barnhart et al, 2003), which is not bound by FimD $D_{\mathrm{N}}$ (Nishiyama et al, 2003).

The X-ray structure of the FimD $_{N}(1-125)-$ FimC-FimH $H_{P}$ complex thus predicts that the common element of the interactions of $\mathrm{FimD}_{\mathrm{N}}$ with the four different FimC-subunit complexes (Figure 1) is the contact area between the $\mathrm{N}$ terminal FimC domain and the structured domain 25-125 (Figure 3D). This contact area alone is, however, neither sufficient for binding of FimC-subunit complexes to FimD $_{N}$ (cf. Figure 5), nor for stable binding of the free chaperone to the assembly platform (Saulino et al, 1998; Nishiyama et al, 2003). The fact that FimC alone is not bound by FimD ensures that FimC is released to the periplasm for another reaction cycle as soon as the bound subunit dissociates from the ternary complex and is delivered to the translocation pore.

\section{Conserved hydrophobic interactions dominate the recognition of the FimC-Fim $H_{P}$ complex by $F i m D_{N}(1-125)$}

A striking feature of the N-terminal FimD $\mathrm{D}_{\mathrm{N}}$ tail is the crowding of the three aromatic residues Phe4, Phe8, and Phe22 in the sequence, which make hydrophobic contacts with the FimC-FimH $H_{P}$ complex. As shown in Figures 3B and C, Phe8 protrudes deeply into the hydrophobic core of the FimC$\mathrm{FimH}_{\mathrm{P}}$ interface and interacts with residues Ile90 and Gln104 of FimC. Specific contacts from FimD $\mathrm{N}_{\mathrm{N}}$ to $\mathrm{FimH}_{\mathrm{P}}$ are formed to the $\mathrm{FimH}_{\mathrm{P}}$ residues Gln269 and Ile271 (Figure 3B). The interaction between the globular domain FimD $_{\mathrm{N}}(25-125)$ and the N-terminal FimC domain is stabilized by hydrophobic interactions and hydrogen bonds, as well as by a salt bridge between Asp36 of FimD $_{\mathrm{N}}$ and Arg66 of FimC (Figure 3D). Sequence alignment shows that the corresponding salt bridge is also present in the PapD-PapC contact area (Arg68 in PapD and Asp35 in PapC), which provides a rationale for the finding that the Arg68 in PapD is required for P pilus biogenesis in vivo (Hung et al, 1999) (see also Figure 4). In addition to specific side-chain contacts, there are also mainchain hydrogen bonds between FimC and the $\operatorname{FimD}_{\mathrm{N}}$ core (Figure 3D). Furthermore, a hydrophobic cluster is formed by Leu28 and Tyr33 of FimD ${ }_{\mathrm{N}}$ and Pro52 of FimC, and Gly107 of FimD $_{\mathrm{N}}$ makes hydrophobic contact with Asn63 of FimC. Overall, multiple interactions in the protein-protein interface thus define the specificity of the FimC-FimD contact, making FimC and FimD a functional chaperone/assembly platform pair (Jones et al, 1993).

\section{Biological significance of the recognition of FimC-subunit complexes by Fim $D_{N}$}

In order to test the biological significance of the molecular interactions between $\operatorname{FimD}_{\mathrm{N}}$ and the chaperone-subunit complex observed in the X-ray structure of the $\mathrm{FimD}_{\mathrm{N}^{-}}$ FimC-FimH $H_{P}$ complex, we performed functional tests after replacing individual amino acids in FimD (Phe4Ala, Phe8Ala, Phe22Ala, Tyr33Ala, Asp36Ala, Gln109Ala) or FimC (Leu32Gly, Leu32Glu, Ile90Arg) that form specific contacts in the interface between FimD $_{N}$ and the FimC-FimH $\mathrm{P}_{\mathrm{P}}$ complex (cf. Figure 3). The FimD mutations were first introduced into full-length FimD, and the mutant proteins were tested for their ability to complement FimD deficiency in an E. coli fimD deletion strain through agglutination assays with yeast cells (Mirelman et al, 1980). We then introduced the same mutations into FimD $_{N}$ (1-139), expressed and purified the mutant proteins, and tested them for their ability to form ternary complexes with the FimC$\mathrm{FimH}_{\mathrm{P}}$ complex in vitro. Similarly, the FimC variants Leu32Gly, Leu32Glu, and Ile90Arg were analyzed for FimC complementation in the fimC deletion strain $\mathrm{W} 3110 \Delta$ fim C, and the corresponding purified variants were tested for formation of a ternary complex with wild-type FimD $_{\mathrm{N}}(1-139)$ and FimH $_{\mathrm{P}}$. The results from these experiments are summarized in Figure 5, which shows that all the mutations leading to the loss of formation of the ternary complex in vitro also lead to the complete or partial loss of the formation of functional type 1 pili in vivo (cf. also Supplementary Figure S3A).

The FimC variants Leu32Glu and Ile90Arg completely lost biological activity and no longer formed ternary complexes in vitro (Figure 5), showing that the conserved residues Leu32 and Ile90 are required for recognition of chaperone-subunit complexes by FimD ${ }_{\mathrm{N}}$. Only the FimC variant Leu32Gly was active, which provides a rationale for the fact that residue 32 is either Leu or Gly in the entire chaperone family (cf. Figure 4). All FimC variants retained the ability to form the binary complex with $\mathrm{FimH}_{\mathrm{P}}$ (Figure 5B), which was expected given the fact that the FimC residue exchanges are located opposite to the subunit-binding site (Figure 3A). In FimD variants, all amino-acid replacements and truncations in the tail 1-24 completely abolished FimD function, although the variant proteins were expressed at the same level as wild-type FimD (Supplementary Figure S3B). These data explain the finding of $\mathrm{Ng}$ et al (2004) that alanine substitution of Phe3 in 
A

FIMD_ECOLI FOCD_ECOLI FAED ECOLI PAPC_ECOLI SEFC_SALEN HFC1_HAEIN PMFC PROM CAFA_YERPE

IMD ECOLI FOCD ECOLI FAED_ECOLI PAPCECOLI SEFC SALEN HFC1_HAEIN PMFC PROM CAFA_YERPE

\section{$\nabla \nabla \nabla$}

DLYFNPRF L A D DP. QAVA DLSR FENGQELPPGTYRVDIYLNNGYMA. TRD ELYFNRR F L S D P. DAVADLSAFT QGQELPP GVYRIVDI Y L N D T Y I S. . TRD GE KL DMSFI QGGG. GVNPEVWAALNG.SYAPGRYLIVDLSLNGKEAG..K K I VEF NT DVIL DAADK. KNI DFTRF SEAGYVLPGQYLLDVIVNGQSISPASLO QYNFDY GSL SLPP. GENASFL SVET... LP GNYVIVDVYLN NQLKE. T T E EDQF DAS L WGGGS. VL GI DFARFNVKNAVLPGRYEIA QI Y VNNEEKG. . ES SVEFNI HMLDAEDR. DNVDLSRFSTSNYII P GMYYLDI RLNGRDFP..RON

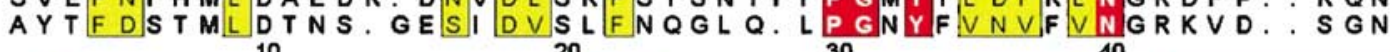

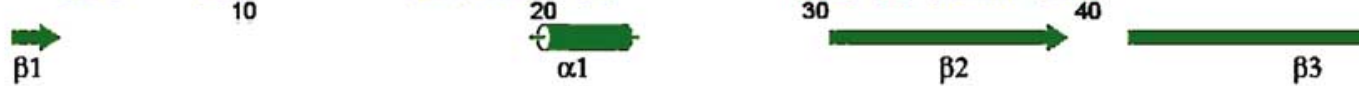

VTFNTGD..... SEQGIVPCLTRAQLIASMGLNTASVAGMNLLADD. ACVP $\checkmark Q F Q M S Q . \cdots$ DGKQLAPCL SPEHMSAMGVNRYAVPGMERLPAD. TCTS

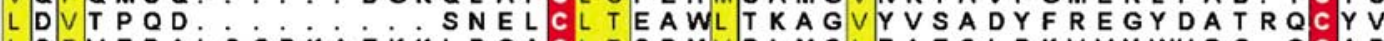
I S FVEPALS GDKAEKKLPQACLTSDMVRLMGLTAESLDKVVYWHDG. QCAD LYFK SMT....... QTLEPCL TKEKLI KYGI AI QELHGL QFDNEQ.. CVL I IFA DN PAT G...... RAELCF T P K L Q E MLDL MDEAIVKS PNSEDD. TCVF

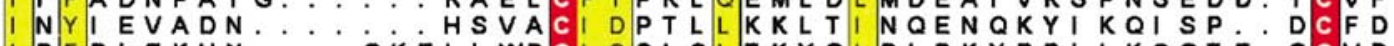
1 DERLEKHN.... GKELLWPLLSSL QL TKYGI DI DKYPDLIKSGTE. QCVD 50

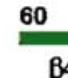

80 90

$\beta 4 \alpha 2$ FIMD_ECOLI
FOCD_ECOLI
FAED_ECOLI
PAPC_ECOLI
SEFC_SALEN
HFC1_HAEIN
PMFC_PROMI
CAFA_YYRPE
LT T MVQDAT AHL DVGQQRLNLT PQAF MSNRARGYI P PE L WDPGINA L T KAPS. VKVDFDVST QSLALSI PQKGLVKMPENVD.... WDYGTSA F H GLPG. VDIRPDTGAGVLR I N MPQA WL Y Y SDAT WL P P S R WD DGI PG L E H S P L K. Y T Y N A A N Q S L L L N A P S K I L S P I D S E I A D E N I WD D G I N A A S D A I P K G T F D Y Q G GD M KL K L E I P Q A L T I R R P R G Y I A P S R W Q T G T N A I S Q L PG. I S I KND GG. V VLDI TLPR S L M KY E ES DWTPPEL WDSGVS G

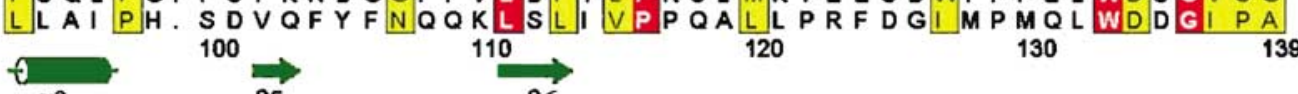
$\alpha 3 \quad \overrightarrow{85} \quad \overrightarrow{66}$
B

FIMC_ECOLI FOCC_ECOLI FAEE_ECOLI HFB1 HAEIN PMFD PROM CAFM_YERPE

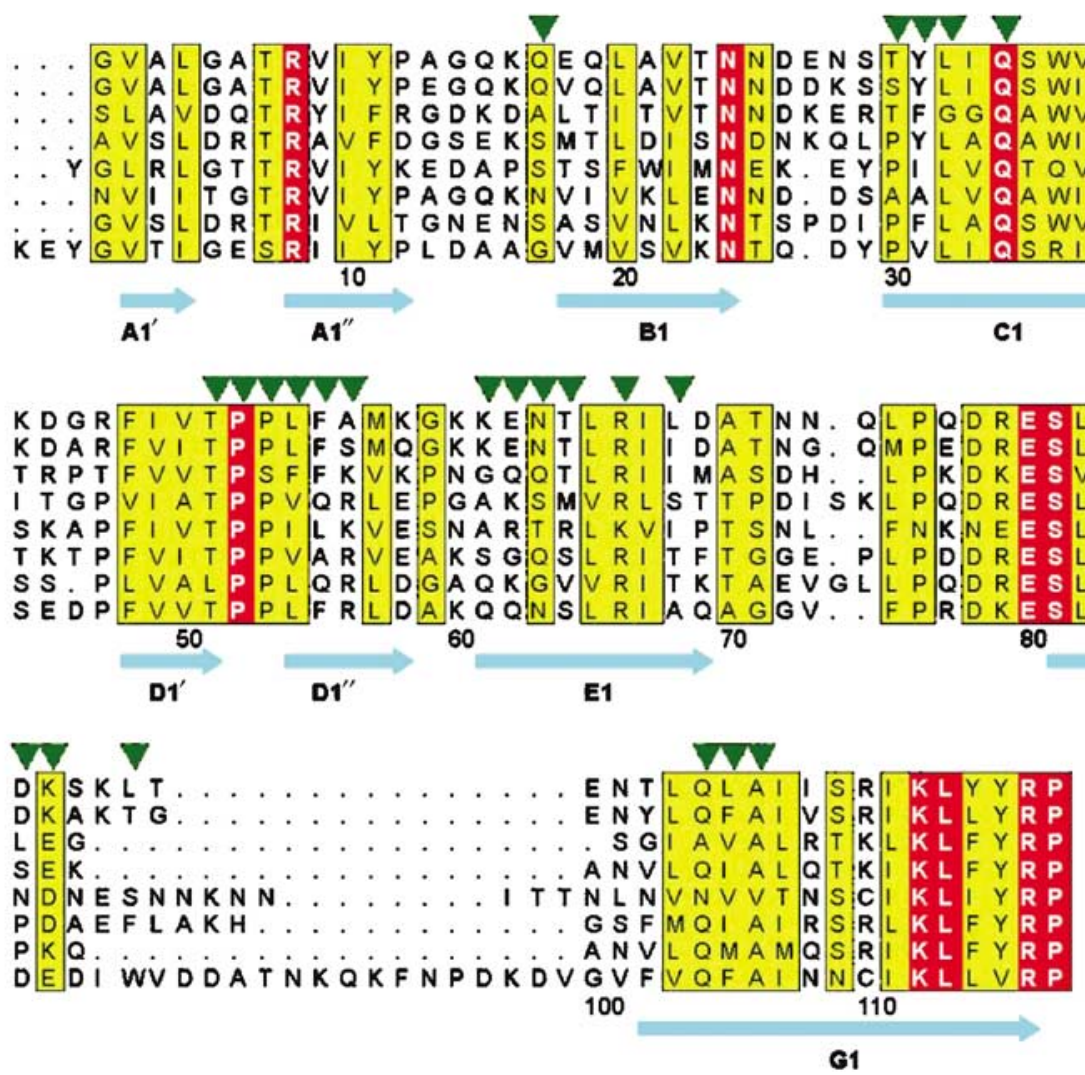

FIMC ECOL FOCC ECOLI FAEE_ECOLI PAPD_ECOLI SEFB SALEN HFB1-HAEIN PMFD_PROM CAFM_YERPE

FIMC_ECOLI
FOCE_ECOLI
FAEE_ECOLI
PAPD_ECOLI
SEFB_SALEN
HFB1_HAEIN
PMFD_PROMI
CAFM_YERPE

$A D G V$ A E G K I VEKD QEKI D D K S ADPKY KE KE 40 . 
A

FimD variants
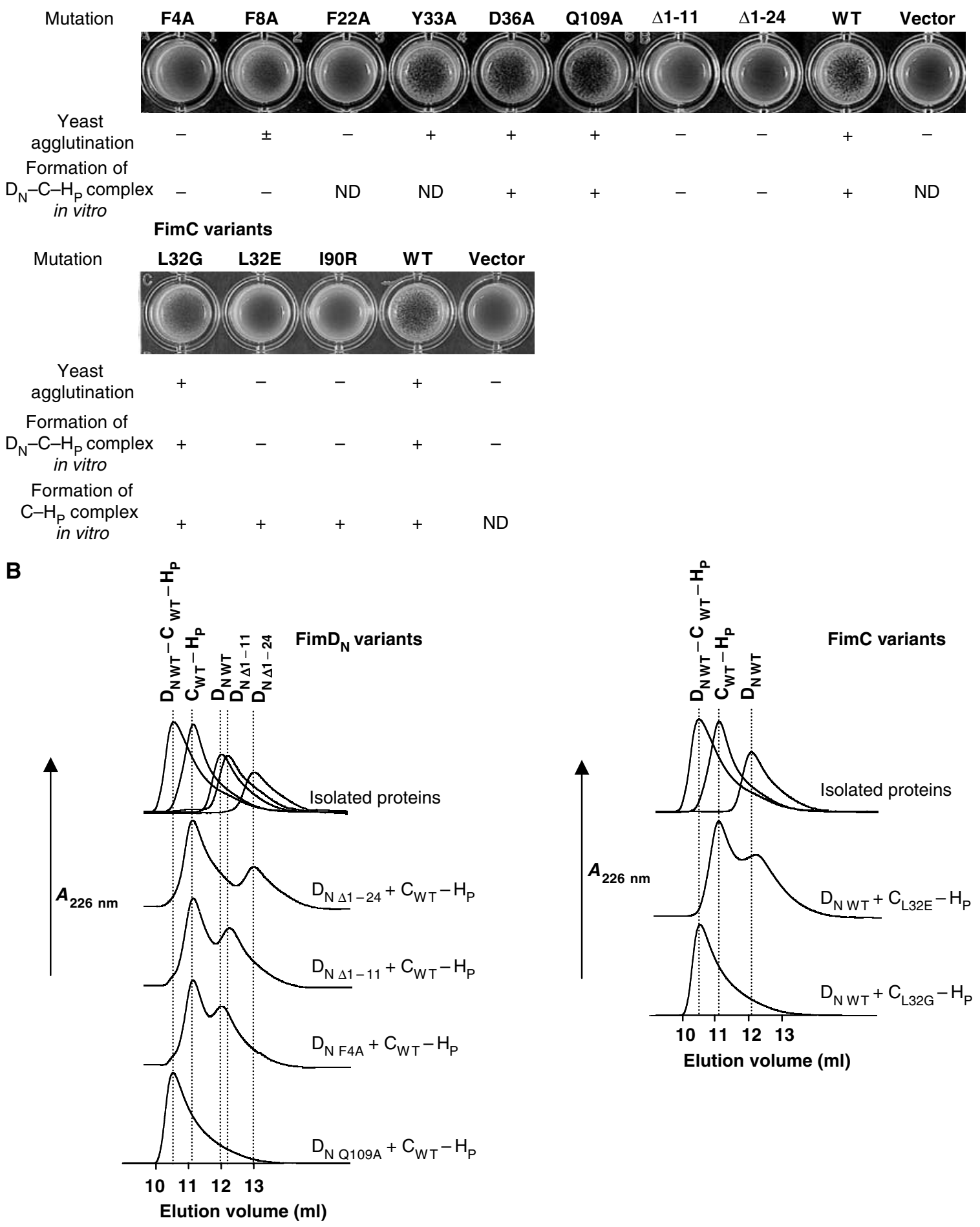

Figure 5 Analysis of amino-acid replacements and deletions in FimD, $\operatorname{FimD}_{\mathrm{N}}(1-139)$, and replacements in FimC with respect to type 1 pilus biogenesis in vivo and formation of ternary $\operatorname{FimD}_{\mathrm{N}}(1-139)-\mathrm{FimC}-\mathrm{FimH}_{\mathrm{P}}$ complexes in vitro. (A) Yeast agglutination assays, probing the formation of functional type 1 pili through agglutination with yeast cells. The E. coli strains W3110 $\Delta$ fimD and W3110 $\Delta$ fimC were transformed with expression plasmids carrying the indicated FimD and FimC variants, respectively. Agglutination intensities are indicated as $(-)$ no agglutination, $( \pm)$ weak or $(+)$ strong. The ability of $\operatorname{FimD}_{\mathrm{N}}(1-139)$ and FimC variants to form the ternary complex as well as the ability of FimC variants to bind $\mathrm{FimH}_{\mathrm{p}}$ in vitro are indicated as 'yes' (+) or 'no' (-). ND, not determined. (B) Analytical gel filtration at $\mathrm{pH} 7.4$ and $25^{\circ} \mathrm{C}$, probing the effect of mutations in FimD $\mathrm{N}_{\mathrm{N}}(1-139)$ or FimC on the formation of the FimD $\mathrm{N}_{\mathrm{N}}(1-139)-\mathrm{FimC}-\mathrm{FimH}_{\mathrm{P}}$ complex.

the N-terminal segment of the $\mathrm{P}$ pilus assembly platform PapC and deletion of residues 3-12 in FimD or residues 2-11 in PapC abolish pilus biogenesis (cf. also Figure 4). In contrast, the FimD replacements Tyr33Ala, Asp36Ala, and
Gln109Ala in the contact area of $\operatorname{FimD}_{\mathrm{N}}(25-125)$ did not disrupt FimD function in vivo. However, isothermal titration calorimetry showed that the affinity of the corresponding FimD $_{N}(1-139)$ variants for the FimC-FimH $H_{P}$ complex was 
lowered $\left(K_{\mathrm{D}}=7.1\right.$ and $4.2 \mu \mathrm{M}$ for the variants Asp36Ala and Gln109Ala, respectively, as compared to $1.2 \mu \mathrm{M}$ for the wildtype protein; Supplementary Table S2). Overall, the FimD mutagenesis experiments indicate that the contacts formed by the N-terminal FimD tail of residues 1-24 make the dominant energetic contributions to the recognition of chaperone-subunit complexes, and are thus crucial for the function of assembly platforms. In particular, the hydrophobic interactions formed by the aromatic residues Phe4 and Phe22 in the N-terminal tail of FimD are indispensable for ternary complex formation. Intriguingly, the positions 4 and 22 of homologous assembly platforms are strongly conserved (Figure 4).

\section{TROSY-NMR chemical shift mapping indicates a movement of the $C$-terminal hinge segment of FimD $D_{N}$ upon binding of the FimC-FimH $H_{P}$ complex}

To further analyze the conformational changes associated with the formation of the ternary FimD $_{N}-$ FimC-FimH $H_{P}$ complex, we mapped chemical shift variations between isolated FimD $_{\mathrm{N}}(1-139)$ and $\operatorname{FimD}_{\mathrm{N}}(1-139)$ in the ternary complex with $\left[{ }^{15} \mathrm{~N},{ }^{1} \mathrm{H}\right]$ TROSY-NMR, using ${ }^{15} \mathrm{~N},{ }^{2} \mathrm{H}$-labeled $\operatorname{FimD}_{\mathrm{N}}(1-$ 139) and unlabeled FimC-FimH $H_{P}$ complex. Figure $2 \mathrm{E}$ shows that only eight residues in $\operatorname{FimD}_{\mathrm{N}}(1-139)$ have $\left[{ }^{15} \mathrm{~N},{ }^{1} \mathrm{H}\right]$ chemical shift variations, $\Delta \delta_{\mathrm{Av}}$, larger than 0.075 , namely Asn5, Arg7, Asp36, Arg47, Arg125, Glu131, Trp133, and Asp134. Large chemical shift changes for Asn5, Arg7, and Asp36 can readily be rationalized by the X-ray structure of the ternary FimD $_{N}(1-125)-$ FimC-FimH $H_{P}$ complex, since these residues form specific contacts either with FimC or the FimH pilin domain. The extensive chemical shift changes observed for Arg125, Glu131, Trp133, and Asp134 suggest a movement of the $\mathrm{C}$-terminal hinge segment upon binding of the FimC-FimH $H_{\mathrm{P}}$ complex. When we modeled the C-terminal hinge segment 126-139 of the NMR structure of FimD (25-139) into the X-ray structure of the ternary complex, we observed steric clashes between the side chain of Asn138 in FimD and the surface of FimC for all calculated NMR conformers (Supplementary Figure S2B). Particularly significant is the large chemical shift change of Arg47. In the NMR structure of FimD $_{N}(25-125)$ (shown in red in Supplementary Figure S2C) and in the X-ray structure of the ternary complex (shown in green in Supplementary Figure S2C), the side chain of Arg47 adopts a bent conformation. In the X-ray structure and in some of the NMR conformers of FimD $_{\mathrm{N}}$ (25-125), the guanidinium group acts as a hydrogen bond donor to the main-chain carbonyl oxygen of Asp48. This conformation of Arg47 is not observed in the NMR structure of FimD $_{\mathrm{N}}(25-139)$ (shown in blue in Supplementary Figure S2C), since it would lead to clashes with the residues Pro130, Trp133, and Pro135 of the C-terminal hinge segment. Instead, the side chain of Arg47 protrudes into the bulk solvent (Supplementary Figure S2C). These observations suggest that, upon binding of the FimC-FimH $\mathrm{P}_{\mathrm{P}}$ complex, the side chain of Arg47 is set free to move, and most likely assumes again the hydrogen-bonded conformation observed in the absence of the $\mathrm{C}$-terminal hinge segment (i.e., in the X-ray structure, and in the NMR structure of $\operatorname{FimD}_{\mathrm{N}}(25-125)$ ). Most importantly, the above-mentioned model considerations reveal that FimC and the bound subunit would collide with the hydrophobic part of the outer membrane, if one assumes that the first $\beta$-strand of the transmembrane $\beta$-barrel of FimD starts with residue 138, as indicated by the topology prediction program described by Martelli et al (2002). Taken together with the observation that segment 126-139 of FimD $_{\mathrm{N}}(1-139)$ was proteolytically degraded only when complexed with FimC-FimH $\mathrm{P}_{\mathrm{P}}$, this observation provides convincing evidence for a model in which a partial or complete displacement of the C-terminal hinge segment of FimD $_{N}$ relative to the folded core (residues 1-125) occurs upon formation of the ternary complex. FimD $_{N}(1-139)$ would thus exist in an 'open' conformation capable of binding chaperone-subunit complexes, and a 'closed' conformation in which Trp133 is bound to its pocket on the surface of the FimD $_{N}$ core 25-125. A movement of FimD $_{N}(1-139)$ could also be related to the delivery of pilus subunits to the translocation pore and to the release of the free chaperone to the periplasm for the next assembly cycle.

\section{Concluding remarks}

The E. coli type 1 pilus system serves as a prototype for adhesive surface organelles produced by a large number of pathogenic bacteria. The presently described structural studies on FimD $\mathrm{N}_{\mathrm{N}}$, with and without bound chaperone-subunit complex, shed light on the molecular basis of the initial interaction of the assembly platform with the chaperonesubunit complex. To further elucidate the cascade of reaction steps following this initial binding event, additional biochemical and structural information on the full-length outer membrane assembly platform will be required. Understanding the molecular details of the mode of action of assembly platforms can be expected to provide a basis for the development of novel antimicrobial agents that would block the assembly of the virulence determinants and hence their adhesion to host tissue.

\section{Materials and methods}

\section{Plasmids}

Mutations corresponding to amino-acid replacements were introduced into the following plasmids, using the QuikChange site-directed mutagenesis kit (Stratagene). For FimD variants, plasmid pfimD $D_{\text {his }}$ was used, which contains the entire fimD gene with a C-terminal hexahistidine tag. This plasmid was generated by cloning the genetic fimD sequence into pBAD30 (Guzman et al, 1995) via the KpnI and HindIII restriction sites. The plasmid pfimC-T7term served as template for mutagenesis of fimC. It contains the fimC gene under the control of the $\mathrm{T} 7$ promoter. Amino-acid replacements for in vitro mutagenesis experiments were introduced into the following plasmids: pfimD $_{\mathrm{N}}$ (Nishiyama et al, 2003), encoding residues 1-139 of mature FimD, was used as the template for N-terminal FimD constructs, and for the construction of the truncated FimD $_{\mathrm{N}}$ variants FimD $_{\mathrm{N}}(25-139)$, FimD $_{\mathrm{N}}(1-125)$, and FimD $_{\mathrm{N}}(25-125)$. pCT-FimH-FimC (Vetsch et al, 2002) was used for mutagenesis of the fimc gene. The nucleotide sequences of all the plasmids used in this study are available upon request.

\footnotetext{
NMR sample preparation and data collection

${ }^{13} \mathrm{C},{ }^{15} \mathrm{~N}$-labeled $\mathrm{FimD}_{\mathrm{N}}$ constructs were obtained by growing $E$. coli strain HM125 carrying the appropriate plasmids in minimal medium containing ${ }^{13} \mathrm{C}_{6}-\beta$-glucose and ${ }^{15} \mathrm{NH}_{4} \mathrm{Cl}$ as the sole carbon and nitrogen sources, respectively. Uniformly deuterated and ${ }^{15} \mathrm{~N}$ labeled FimD $D_{\mathrm{N}}(1-139)$ was obtained by growing cells in minimal medium containing $99 \%{ }^{2} \mathrm{H}_{2} \mathrm{O},{ }^{12} \mathrm{C}_{6}-\beta$-glucose, and ${ }^{15} \mathrm{NH}_{4} \mathrm{Cl}$. All NMR measurements were performed at $20^{\circ} \mathrm{C}$ and $\mathrm{pH}$ 7.0, either on a Bruker DRX 500 spectrometer equipped with a cryogenic probe head, or on Bruker DRX 750 and 900 spectrometers.

For the backbone resonance assignment, the following experiments were recorded: 3D HNCA, 3D HNCACB, 3D CBCA(CO)NH,
} 
3D HNCO, 3D HC(C)H-TOCSY, and 3D HC(C)H-COSY (Wider, 1998). Distance constraints were obtained from three NOE experiments with mixing times of $50 \mathrm{~ms}$, that is, $3 \mathrm{D}{ }^{15} \mathrm{~N}$-resolved $\left[{ }^{1} \mathrm{H},{ }^{1} \mathrm{H}\right]$ NOESY, and two 3D ${ }^{13} \mathrm{C}$-resolved $\left[{ }^{1} \mathrm{H},{ }^{1} \mathrm{H}\right]$ NOESY spectra with the ${ }^{13} \mathrm{C}$ carrier frequency in the aliphatic or aromatic regions, respectively. The data sets used for obtaining the sequence-specific resonance assignments were interactively peak picked using the programs XEASY (Bartels et al, 1995) and CARA (R Keller et al, unpublished).

The assignments of the cross-peaks in the $2 \mathrm{D}\left[{ }^{15} \mathrm{~N},{ }^{1} \mathrm{H}\right] \mathrm{TROSY}$ spectra (Pervushin et al, 1998) of $\mathrm{FimD}_{\mathrm{N}}(1-139)$ in the ternary complex with FimC and $\mathrm{FimH}_{\mathrm{P}}$ were obtained in two steps: First, the backbone ${ }^{15} \mathrm{~N},{ }^{1} \mathrm{H}^{\mathrm{N}}$ chemical shift assignments from free FimD ${ }_{\mathrm{N}}$ were mapped onto the $2 \mathrm{D}\left[{ }^{15} \mathrm{~N},{ }^{1} \mathrm{H}\right]$ TROSY spectrum of $\operatorname{FimD}_{\mathrm{N}}(1-$ 139 ) in the complex. Second, the resulting tentative assignments were confirmed by sequential ${ }^{1} \mathrm{H}^{\mathrm{N}}-{ }^{1} \mathrm{H}^{\mathrm{N}}$ connectivities obtained from a $3 \mathrm{D}{ }^{15} \mathrm{~N}$-resolved $\left[{ }^{15} \mathrm{~N},{ }^{1} \mathrm{H}\right] \mathrm{NOESY}$ spectrum.

Measurements of heteronuclear NOEs were performed at $20^{\circ} \mathrm{C}$ on a Bruker DRX 750 spectrometer. The NOE spectra and the reference spectra were integrated using XEASY.

\section{NMR structure calculation}

The NOESY spectra were automatically analyzed with the new inhouse software packages ATNOS (Herrmann et al, 2002b) for automated peak picking and NOE identification in 2D homonuclear and 3D heteronuclear-resolved NOESY spectra, and CANDID (Herrmann et al, 2002a) for automated NOE assignment of NOESY cross-peaks. The program DYANA (Guntert et al, 1997) was used to perform simulated annealing in torsion angle space. The input for ANTOS/CANDID/DYANA consisted of the chemical shifts obtained from the sequence-specific resonance assignment, and of the three aforementioned NOESY spectra. The standard protocol with seven cycles of peak picking, NOE assignment, and 3D structure calculation was applied (Herrmann et al, 2002a, b). During the first six cycles of computation, ambiguous constraints (Nilges, 1997) were used. At the outset of the spectral analysis, highly permissive criteria were used to identify a comprehensive set of peaks in the NOESY spectra, and only the knowledge of the covalent polypeptide structure and the chemical shifts were exploited to guide NOE cross-peak identification and NOE assignment. In the second and subsequent cycles, the intermediate protein three-dimensional structures served as an additional guide for the interpretation of the NOESY data. The output of ANTOS/CANDID/DYANA consisted of assigned NOE peak lists for each input spectrum, and a final set of meaningful upper limit distance constraints that constituted the input for the DYANA 3D structure calculation algorithm. For each cycle of $3 \mathrm{D}$ structure calculation, torsion angle constraints for the backbone dihedral angles derived from $\mathrm{C}^{\alpha}$ chemical shifts (Spera and Bax, 1991) were added to the CANDID output. For the final structure calculation in cycle 7 , only those distance constraints were retained that could be unambiguously assigned based on the protein three-dimensional structure from cycle 6 . The 20 conformers with the lowest residual DYANA target function values obtained from cycle 7 were energy-refined in a water shell with the program OPALp (Luginbuhl et al, 1996; Koradi et al, 2000), using the AMBER force field. The program MOLMOL (Koradi et al, 1996) was used to analyze the protein structure and to prepare the figures of the NMR structures. The atomic coordinates of 20 energyminimized DYANA conformers each of FimD $_{\mathrm{N}}(25-125)$ and FimD $_{\mathrm{N}}(25-139)$ have been deposited in the PDB, with entry codes 1ZDX and $1 \mathrm{ZDV}$, respectively.

\section{References}

Baorto DM, Gao Z, Malaviya R, Dustin ML, van der Merwe A, Lublin DM, Abraham SN (1997) Survival of FimH-expressing enterobacteria in macrophages relies on glycolipid traffic. Nature 389: 636-639

Barnhart MM, Sauer FG, Pinkner JS, Hultgren SJ (2003) Chaperonesubunit-usher interactions required for donor strand exchange during bacterial pilus assembly. J Bacteriol 185: 2723-2730

Bartels C, Xia TH, Billeter M, Guntert P, Wuthrich K (1995) The program XEASY for computer-supported NMR spectral-analysis of biological macromolecules. J Biomol NMR 6: 1-10

\section{Crystallization and $X$-ray structure determination of the ternary complex}

FimD $_{\mathrm{N}}(1-125)$ and the FimC-FimH $\mathrm{P}_{\mathrm{P}}$ complex were expressed and purified as described (Nishiyama et al, 2003). The ternary complex was obtained by mixing equimolar amounts of $\operatorname{FimD}_{\mathrm{N}}(1-125)$ and $\mathrm{FimC}-\mathrm{FimH}_{\mathrm{P}}$, and subsequent purification on a Superdex 75 26/60 size-exclusion column (Amersham Biosciences) equilibrated in $20 \mathrm{mM}$ sodium phosphate (pH 7.4), $115 \mathrm{mM} \mathrm{NaCl}$. The homogenous complex was dialyzed against $10 \mathrm{mM}$ Tris/HCl (pH 8.0) and concentrated. Using the sitting drop vapor diffusion method, we obtained two different crystal forms. Crystals with space group $\mathrm{P}_{3}$ (form A) with three complexes per asymmetric unit were obtained using a reservoir solution containing $0.02 \mathrm{M}$ TAPS/NaOH (pH 9.2) and $18 \%$ PEG 5000 MME. Crystals with space group $\mathrm{P}_{1} 2_{1} 2_{1}$ (form B) with one complex per asymmetric unit were obtained using a reservoir solution containing $0.1 \mathrm{M}$ MES/NaOH $(\mathrm{pH}$ 6.5) and $15 \%$ PEG 6000.

Diffraction data were collected using synchrotron radiation at the Swiss Light Source and the structure of the ternary complex was solved by molecular replacement with AMoRe (Navaza, 1994) and refined with CNS (Brunger et al, 1998). The data collection and refinement statistics are given in Table II. Details of data collection, structure solution, and refinement are given in Supplementary data. The atomic coordinates and structure factors have been deposited in the PDB with entry code 1ZE3.

\section{Characterization of FimC and FimD variants}

All variants of FimD $D_{\mathrm{N}}$ were expressed in E. coli strain HM125 and purified as described previously for wild-type FimD $_{\mathrm{N}}$ (Nishiyama et al, 2003). Periplasmic expression and purification of complexes between FimC variants and $\mathrm{FimH}_{\mathrm{P}}$ was carried out as described (Vetsch et al, 2002).

Yeast agglutination assays were performed as previously described (Nishiyama et al, 2003) with E. coli strains W3110 $\Delta$ fimC and W3110 $\Delta$ fimD transformed with plasmids encoding the respective wild-type proteins or variants. W3110 $\Delta$ fimC and W3110 $\Delta$ fimD were constructed from E. coli K12 wild-type strain W3110 by allelic exchange (Hamilton et al, 1989) and the Red disruption system (Datsenko and Wanner, 2000), respectively.

Analytical gel-filtration experiments were carried out at $\mathrm{pH} 7.4$ and $25^{\circ} \mathrm{C}$ with initial protein concentrations of $60 \mu \mathrm{M}$ as described (Nishiyama et al, 2003).

Protein concentrations were determined via the specific protein absorbance at $280 \mathrm{~nm}$.

\section{Supplementary data}

Supplementary data are available at The EMBO Journal Online.

\section{Acknowledgements}

We thank the staff of the beamline X06SA at the Swiss Light Source (Villigen, Switzerland), especially Takashi Tomizaki, for support in X-ray data collection. We are also grateful to Beat Blattmann (University of Zurich) for help in protein crystallization, René Brunisholz (Protein Service Laboratory, ETHZ) for Edman sequencing, and Peter Tittmann for assistance with electron microscopy. MN thanks Kaspar Hollenstein for his valuable comments on the manuscript. This project was funded by the Schweizerische Nationalfonds (grant 3100AO-100787 to RG), the ETH Zurich, and the University of Zurich within the framework of the NCCR Structural Biology program.

Barton GJ (1993) ALSCRIPT: a tool to format multiple sequence alignments. Protein Eng 6: 37-40

Berman HM, Westbrook J, Feng Z, Gilliland G, Bhat TN, Weissig H, Shindyalov IN, Bourne PE (2000) The Protein Data Bank. Nucleic Acids Res 28: 235-242

Brunger AT, Adams PD, Clore GM, DeLano WL, Gros P, GrosseKunstleve RW, Jiang JS, Kuszewski J, Nilges M, Pannu NS, Read RJ, Rice LM, Simonson T, Warren GL (1998) Crystallography \& NMR system: a new software suite for macromolecular structure determination. Acta Crystallogr D 54: 905-921 
Bullitt E, Makowski L (1995) Structural polymorphism of bacterial adhesion pili. Nature 373: 164-167

Choudhury D, Thompson A, Stojanoff V, Langermann S, Pinkner J, Hultgren SJ, Knight SD (1999) X-ray structure of the FimC-FimH chaperone-adhesin complex from uropathogenic Escherichia coli. Science 285: 1061-1066

Datsenko KA, Wanner BL (2000) One-step inactivation of chromosomal genes in Escherichia coli K-12 using PCR products. Proc Natl Acad Sci USA 97: 6640-6645

Guntert P, Mumenthaler C, Wuthrich K (1997) Torsion angle dynamics for NMR structure calculation with the new program DYANA. J Mol Biol 273: 283-298

Guzman LM, Belin D, Carson MJ, Beckwith J (1995) Tight regulation, modulation, and high-level expression by vectors containing the arabinose PBAD promoter. J Bacteriol 177: 4121-4130

Hahn E, Wild P, Hermanns U, Sebbel P, Glockshuber R, Haner M, Taschner N, Burkhard P, Aebi U, Muller SA (2002) Exploring the 3D molecular architecture of Escherichia coli type 1 pili. J Mol Biol 323: $845-857$

Hamilton CM, Aldea M, Washburn BK, Babitzke P, Kushner SR (1989) New method for generating deletions and gene replacements in Escherichia coli. J Bacteriol 171: 4617-4622

Harms N, Oudhuis WC, Eppens EA, Valent QA, Koster M, Luirink J, Oudega B (1999) Epitope tagging analysis of the outer membrane folding of the molecular usher FaeD involved in K88 fimbriae biosynthesis in Escherichia coli. J Mol Microbiol Biotechnol 1: 319-325

Henderson NS, So SS, Martin C, Kulkarni R, Thanassi DG (2004) Topology of the outer membrane usher PapC determined by sitedirected fluorescence labeling. J Biol Chem 279: 53747-53754

Herrmann T, Guntert P, Wuthrich K (2002a) Protein NMR structure determination with automated NOE assignment using the new software CANDID and the torsion angle dynamics algorithm DYANA. J Mol Biol 319: 209-227

Herrmann T, Guntert P, Wuthrich K (2002b) Protein NMR structure determination with automated NOE-identification in the NOESY spectra using the new software ATNOS. J Biomol NMR 24: 171-189

Holm L, Sander C (1998) Touring protein fold space with Dali/FSSP. Nucleic Acids Res 26: 316-319

Hung DL, Knight SD, Hultgren SJ (1999) Probing conserved surfaces on PapD. Mol Microbiol 31: 773-783

Jacob-Dubuisson F, Striker RT, Hultgren SJ (1994) Chaperoneassisted self-assembly of pili independent of cellular energy. J Biol Chem 269: 12447-12455

Jones CH, Pinkner JS, Nicholes AV, Slonim LN, Abraham SN, Hultgren SJ (1993) FimC is a periplasmic PapD-like chaperone that directs assembly of type 1 pili in bacteria. Proc Natl Acad Sci USA 90: 8397-8401

Jones CH, Pinkner JS, Roth R, Heuser J, Nicholes AV, Abraham SN, Hultgren SJ (1995) FimH adhesin of type 1 pili is assembled into a fibrillar tip structure in the Enterobacteriaceae. Proc Natl Acad Sci USA 92: 2081-2085

Klemm P, Christiansen G (1990) The fimD gene required for cell surface localization of Escherichia coli type 1 fimbriae. Mol Gen Genet 220: 334-338

Koradi R, Billeter M, Guntert P (2000) Point-centered domain decomposition for parallel molecular dynamics simulation. Comput Phys Commun 124: 139-147

Koradi R, Billeter M, Wuthrich K (1996) MOLMOL: a program for display and analysis of macromolecular structures. J Mol Graph 14: $51-55$

Laskowski RA, MacArthur MW, Moss DS, Thornton JM (1993) PROCHECK: a program to check the stereochemical quality of protein structure. J Appl Crystallogr 26: 283-291

Li H, Qian L, Chen Z, Thibault D, Liu G, Liu T, Thanassi DG (2004) The outer membrane usher forms a twin-pore secretion complex. J Mol Biol 344: 1397-1407

Luginbuhl P, Guntert P, Billeter M, Wuthrich K (1996) The new program OPAL for molecular dynamics simulations and energy refinements of biological macromolecules. J Biomol NMR 8: 136-146

Martelli PL, Fariselli P, Krogh A, Casadio R (2002) A sequenceprofile-based HMM for predicting and discriminating beta barrel membrane proteins. Bioinformatics 18 (Suppl 1): S46-S53
Martinez JJ, Mulvey MA, Schilling JD, Pinkner JS, Hultgren SJ (2000) Type 1 pilus-mediated bacterial invasion of bladder epithelial cells. EMBO J 19: 2803-2812

Mirelman D, Altmann G, Eshdat Y (1980) Screening of bacterial isolates for mannose-specific lectin activity by agglutination of yeasts. J Clin Microbiol 11: 328-331

Mulvey MA, Lopez-Boado YS, Wilson CL, Roth R, Parks WC, Heuser J, Hultgren SJ (1998) Induction and evasion of host defenses by type 1-piliated uropathogenic Escherichia coli. Science 282: 1494-1497

Navaza J (1994) AMoRe: an automated package for molecular replacement. Acta Crystallogr A 50: 157-163

Ng TW, Akman L, Osisami M, Thanassi DG (2004) The usher N terminus is the initial targeting site for chaperone-subunit complexes and participates in subsequent pilus biogenesis events. J Bacteriol 186: 5321-5331

Nilges M (1997) Ambiguous distance data in the calculation of NMR structures. Fold Des 2: S53-S57

Nishiyama M, Vetsch M, Puorger C, Jelesarov I, Glockshuber R (2003) Identification and characterization of the chaperone-subunit complex-binding domain from the type 1 pilus assembly platform FimD. J Mol Biol 330: 513-525

Nooren IM, Thornton JM (2003) Structural characterisation and functional significance of transient protein-protein interactions. J Mol Biol 325: 991-1018

Pellecchia M, Sebbel P, Hermanns U, Wuthrich K, Glockshuber R (1999) Pilus chaperone FimC-adhesin FimH interactions mapped by TROSY-NMR. Nat Struct Biol 6: 336-339

Pervushin K, Riek R, Wider G, Wüthrich K (1998) Attenuated T2 relaxation by mutual cancellation of dipole-dipole coupling and chemical shift anisotropy indicates an avenue to NMR structures of very large biological macromolecules in solution. Proc Natl Acad Sci USA 94: 12366-12371

Sauer FG, Futterer K, Pinkner JS, Dodson KW, Hultgren SJ, Waksman G (1999) Structural basis of chaperone function and pilus biogenesis. Science 285: 1058-1061

Sauer FG, Pinkner JS, Waksman G, Hultgren SJ (2002) Chaperone priming of pilus subunits facilitates a topological transition that drives fiber formation. Cell 111: 543-551

Sauer FG, Remaut H, Hultgren SJ, Waksman G (2004) Fiber assembly by the chaperone-usher pathway. Biochim Biophys Acta 1694: 259-267

Saulino ET, Bullitt E, Hultgren SJ (2000) Snapshots of ushermediated protein secretion and ordered pilus assembly. Proc Natl Acad Sci USA 97: 9240-9245

Saulino ET, Thanassi DG, Pinkner JS, Hultgren SJ (1998) Ramifications of kinetic partitioning on usher-mediated pilus biogenesis. EMBO J 17: 2177-2185

Spera S, Bax A (1991) Empirical correlation between protein backbone conformation and $\mathrm{C} \alpha$ and $\mathrm{C} \alpha 13 \mathrm{C}$ nuclear magnetic resonance chemical-shifts. J Am Chem Soc 113: 5490-5492

Thanassi DG, Hultgren SJ (2000) Multiple pathways allow protein secretion across the bacterial outer membrane. Curr Opin Cell Biol 12: $420-430$

Thompson JD, Higgins DG, Gibson TJ (1994) CLUSTAL W: improving the sensitivity of progressive multiple sequence alignment through sequence weighting, position-specific gap penalties and weight matrix choice. Nucleic Acids Res 22: 4673-4680

Vetsch M, Puorger C, Spirig T, Grauschopf U, Weber-Ban EU, Glockshuber R (2004) Pilus chaperones represent a new type of protein-folding catalyst. Nature 431: 329-333

Vetsch M, Sebbel P, Glockshuber R (2002) Chaperone-independent folding of type 1 pilus domains. J Mol Biol 322: 827-840

Wider G (1998) Technical aspects of NMR spectroscopy with biological macromolecules and studies of hydration in solution. Prog NMR Spectrosc 32: 132-275

Zavialov AV, Berglund J, Pudney AF, Fooks LJ, Ibrahim TM, MacIntyre S, Knight SD (2003) Structure and biogenesis of the capsular F1 antigen from Yersinia pestis: preserved folding energy drives fiber formation. Cell 113: 587-596

Zhou G, Mo WJ, Sebbel P, Min G, Neubert TA, Glockshuber R, Wu XR, Sun TT, Kong XP (2001) Uroplakin Ia is the urothelial receptor for uropathogenic Escherichia coli: evidence from in vitro FimH binding. J Cell Sci 114: 4095-4103 